\title{
O MARKETING DO PERSONAL TRAINER NA REDE SOCIAL INSTAGRAM
}

\author{
RIEBAU, Amanda Karoline; CARDOSO, Rafael Garcia e BOURSCHEID, Débora
}

Goulart

Acesso DOI: http://dx.doi.org/10.34059/ciejop.2019v27i1-15

\section{RESUMO}

Introdução: $O$ assunto do referido trabalho é sobre o marketing do personal trainer. O tema abordou uma análise dos assuntos divulgados na rede social Instagram pelos personal trainers da cidade de Cascavel/PR. Objetivo: Analisar a utilização do marketing profissional do personal trainer nos Posts na rede social Instagram. A pesquisa foi qualiquantitativa fenomenológica realizada de maneira longitudinal. A amostra foram páginas do Instagram de personal trainers renomados da cidade de Cascavel/PR. Como instrumento de pesquisa foi utilizado imagens e conteúdos publicados na rede social Instagram. A análise se deu a partir do aplicativo Fanpage karma. Também foram realizados cálculos de frequência e média dos Posts publicados. Para o cálculo do engajamento utilizou-se a seguinte formula: \% de Engajamento $=($ Total de curtidas $\times 1+$ Total de comentários $\times 2) \div($ número de seguidores da página no período da coleta de dados $x$ número de publicações no período em estudo) $\times 100$. Os principais resultados foi que a maior eficiência de alcance de marketing se deu nas publicações que envolveram a vinculação da imagem "corpo" com o conteúdo "treino", com aproximadamente com o mesmo alcance se teve a união da imagem "exercício", com o conteúdo "motivacional". Conclui-se que existe uma necessidade de maior competência destes profissionais na utilização da ferramenta Instagram para a venda do seu produto.

Palavra-chave: Personal Trainer, Marketing, Instagram

\section{THE PERSONAL TRAINER MARKETING IN THE SOCIAL MEDIA INSTAGRAM}

\section{ABSTRACT}

Introduction: The subject of this academic work is the marketing of personal trainers. The subject will address a content analyse of what the personal trainers in cascavel posts in the social media. Objetctive: analyse the personal trainer's use of professional marketing in social media Instagram. The research will be focused on quantity and quality, made longitudinally. The population and sample are Instagram accounts of famous personal trainers in Cascavel, state of Paraná. Methodology: The reasearch will be supported by the social media Instagram and the app fanpage karma. They correspond to the frequency and average calculations of the published Posts. For the calculation of the engagement, the following formula was used:\% of 
engagement $=($ total of tanned $\times 1+$ total comments $\times 2) \div) \times 100$. The results of the results were a greater efficiency of marketing offer in the surveys that approached the image of the "body" image with the goal of "training" with approximately the same scope if the union of the image "exercise", with the content "motivational." You can use the tool to download Instagram for the sale of your product.

Key words: Personal Trainer, Marketing, Instagram.

\section{INTRODUÇÃO}

Podemos definir o personal trainer como um profissional de Educação Física, que planeja e acompanha o treinamento individualizado de acordo com o objetivo do aluno/cliente, respeitando sua individualidade biológica (DOMINGUES, 2015).

A atuação do personal trainer se difere dos trabalhos tradicionais, pois estes profissionais trabalham de forma autônoma, não possuindo direito de férias, direitos trabalhistas, entre outros requisitos que os trabalhos em geral proporcionam, em grande parte as contratações de alunos são realizadas de maneira informal, assim podendo ocorrer mudanças com o passar do tempo, gerando uma certa instabilidade para estes profissionais (BOSSLE, 2009).

Por ser um profissional autônomo tem se utilizado do marketing para atrair alunos e ter a constância dos demais, desta forma tem se considerado alguns locais para a realização do marketing entre elas destaca-se as mídias sociais, que nos dias atuais tornou-se fundamental para pequenas e grandes empresas a utilização deste meio, pois facilita a relação da empresa com o consumidor deste que seja utilizada de forma adequada (SANTOS, 2012).

O profissional de Educação física que trabalha como personal trainer muitas vezes não possui conhecimento sobre a área do marketing, pois na graduação destes em grande maioria são ofertados apenas uma disciplina de marketing e administração e com isso acabam tendo dificuldade em sua atuação profissional, pois o marketing auxilia na busca de clientes e também na fidelização dos demais (SPACOV, 2016).

O marketing digital veio do marketing tradicional, que são procedimentos estratégicos, econômicos e sociais utilizadas no meio eletrônico, que tem como 
objetivo a divulgação de trabalhos e produtos, com mais facilidade e liberdade para os usuários (CARDOSO; PINTO, 2011; GOMES; REIS, 2016).

Para a divulgação de produtos e trabalhos, atualmente empresas que querem realizar promoções e propagandas estão usando a web como forma de divulgação, pois possuem baixo custo e atingem o público alvo rapidamente, em questão de horas pode circular por todo o mundo, apenas com o compartilhamento das pessoas, e uma propaganda pode ter grande influência na vida dos consumidores (RAMOS, 2015).

O marketing pessoal é uma maneira de reforçar as competências e valores de cada pessoa, direcionando seus comportamentos para assim obter um bom uso de suas habilidades, além disso o marketing pessoal pode contribuir no aspecto profissional, visto que tem como característica aparência, atitude, percepção, competência, boa apresentação, comportamento e empatia, desta forma auxiliam na vida pessoal e profissional (BRUGGER; PRATES; SILVA, 2016).

Nos dias atuais existem diversas redes sociais, entre elas se destaca 0 aplicativo Instagram, que foi criado na Califórnia por Mike Krieger e por Kevin Systrom, em 2010, a rede social foi criada especificamente para smartphones, em seu início era apenas disponível para aplicativos apple, mas com o seu sucesso foi liberado também para os sistemas android, com apenas três meses o Instagram atingiu 1 milhão de usuários, atualmente pode-se monitorar o aplicativo pelo computador, mas as postagens apenas são realizadas pelo smartphone, e desta forma o aplicativo conta com mais de 500 milhões de usuários (VIEIRA, 2017).

O relacionamento na rede social Instagram consiste nos que chamam de seguidores, onde um usuário pode seguir quantos perfis este quiser, para assim seguir o que estes postam no seu feed, além disso o indivíduo pode dar likes, comentar ou até mesmo mandar mensagens privadas pelo Instagram direct, no qual além de conversar por mensagens de texto podem também enviar vídeos e fotos (VIEIRA, 2017).

O Instagram possui um grande diferencial, as chamadas hashtags, que é uma maneira de agrupamento de assuntos na rede de busca, pois utilizando 
determinada hashtag irá delimitar um contexto na rede social (PELLANDA; STREK, 2017; VIEIRA, 2017).

O objetivo foi analisar a utilização do marketing profissional do personal trainer nos Posts na rede social Instagram.

\section{METODOLOGIA}

Conforme a resolução CNS 510/2016, sobre ética em pesquisa com seres humanos, informações de acesso público: dados que podem ser utilizados na produção de pesquisa e na transmissão de conhecimento e que se encontram disponíveis sem restrição ao acesso dos pesquisadores e dos cidadãos em geral, não estão sujeitos a limitações relacionadas à privacidade, à segurança ou ao controle de acesso.

Trata-se de uma pesquisa quali-quantitativa. Foi realizada de modo longitudinal no período de uma semana (a coleta ocorreu entre os dias 01 de maio a 07 de maio do ano de 2019). A amostra contou com análise de dez casos de profissionais de Educação Física, onde foi utilizado pseudônimo numéricos afim de garantir a não divulgação da sua identidade. Estes atuam como personal trainers no Município de Cascavel/PR. O critério de seleção da amostra foi por profissionais em evidência social no ramo de academia. Destes, foi identificado àqueles com maior número de seguidores na rede social Instagram, e que se utilizam de marketing na rede.

Como procedimento de pesquisa para coleta dos dados, inicialmente foi feito um e-mail para a criação de uma nova conta no Instagram, afim de não haver nenhum vínculo pessoal do pesquisador com o analisado.

Como instrumento de pesquisa, foi utilizado o aplicativo Fanpage Karma, que se encontra nas versões gratuitas e pagas, que no caso para o estudo se utilizou da versão gratuita. Para este estudo foram utilizados dados referentes ao perfil individual, que mostra quantos seguidores ele possui e quantas páginas segue, também foi utilizado a porcentagem de quantidade de posts diários. 
Para a análise do discurso e conteúdo foram criadas 9 categorias, associando discurso (imagem) versus conteúdo (texto dos posts). Para o discurso foi criada as seguintes categorias: corpo, conhecimento, pessoal e exercício, já para o conteúdo outras categorias foram utilizadas, tais como: Equivoco (quando o conteúdo não tinha relação com a imagem), motivacional, treino, marketing (produto ou evento), conhecimento informativo e pessoal. Para estas categorias foi computado a média de porcentagem do engajamento, individual e por categoria, utilizando a fórmula: \% de Engajamento $=($ Total de curtidas $\times 1+$ Total de comentários $\times 2) \div($ número de seguidores da página no período da coleta de dados $\mathrm{x}$ número de publicações no período em estudo) x 100, após foi realizado a média dos valores encontrados.

\section{RESULTADOS}

Os dados a serem apresentados são referentes a 06 personal trainers do sexo masculino e 04 femininos. As análises são referentes a publicações no período de uma semana dos posts da rede social Instagram. Na Tabela 1 observase os dados relacionados as variáveis de número de seguidores, quantidade de pessoas que o personal trainer segue, número de posts publicado durante o período de análise e o número de comentário dos posts. O que pode se observar é que a maioria deles possui um número de seguidores bastante expressivo e seguem muito pouco de seus seguidores.

Tendo em vista que as páginas destes profissionais são abertas ao público possibilita a qualquer pessoa seguir e não necessariamente o profissional tem o interesse de segui-los. Pode-se observar também que a média do número de posts em uma semana foi de 4 posts entre os avaliados, o que indica pouca publicação em arquivo. Contudo, verifica-se pouca adesão do profissional em utilizar esse meio como ferramenta de seu marketing.

Quanto aos comentários não foi verificado uma homogeneidade entre seguidores e a quem os profissionais seguem, e foi visto que os comentários, ou não se associam ao número de seguidores. 
Tabela 1 - Dados do perfil individual dos Personal Trainers.

\begin{tabular}{ccccc}
\hline Sujeito & $\begin{array}{c}\text { Número de } \\
\text { Seguidores }\end{array}$ & Segue & $\begin{array}{c}\text { Número de } \\
\text { Posts }\end{array}$ & C.O \\
\hline 1 & 23.000 & 1.100 & 2 & 113 \\
3 & 11.000 & 1.100 & 1 & 5 \\
4 & 2.800 & 829 & 3 & 16 \\
5 & 2.900 & 2.300 & 2 & 1 \\
6 & 34.000 & 2.800 & 3 & 23 \\
7 & 49.000 & 1.300 & 1 & 11 \\
8 & 112.000 & 3.400 & 4 & 11 \\
9 & 1.900 & 3.400 & 5 & 39 \\
10 & 103.000 & 5.000 & 3 & 52 \\
\hline Total Média & 47.000 & 5.200 & 13 & 95 \\
\hline
\end{tabular}

C.O = Comentários (orgânico);

No Quadro 1 é possível perceber que entre as categorias analisadas o sujeito que obteve maior engajamento foi o sujeito 1 , com $4,32 \%$ e todas as suas postagens são relacionadas ao corpo/treino, já o segundo sujeito com maior engajamento é o sujeito 3 com 1,0555\%. Quanto as categorias analisadas foram calculadas o valor médio de postagens, sendo $66,66 \%$ sobre pessoal/pessoal e $33,33 \%$ em relação a corpo/treino. O terceiro com maior engajamento é o sujeito 6 , com $1,05 \%$ e suas postagens são sobre conhecimento/informativo.

Observando-se assim o sujeito que teve menor engajamento foi o sujeito 7 com $0,02 \%$ e suas postagens eram sobre $50 \%$ corpo/corpo, $25 \%$ corpo/motivacional e $25 \%$ conhecimento/informativo. De modo geral, não é observado uma porcentagem razoável de engajamento dos seguidores às publicações postadas. Neste sentido, de acordo com a literatura onde diz que com o surgimento de uma nova geração de marketing individual que são as redes sociais, deveria haver um rompimento com a comunicação estática e unilateral, ou seja, requerendo uma 
cumplicidade entre aquele que emite a informação para aquele que recebe (O'REILLY, 2007). Sendo assim, em relação aos dados encontrados na presente pesquisa, não foi verificado esta inovação, visto nos percentuais de engajamento encontrado. Contudo, verificou-se que o profissional do Exercício Físico ainda se encontra em estágio inicial no atingimento de resultados do marketing realizado.

Refletindo a respeito disso, questiona-se em que medida o profissional fitness tem conhecimento de todos os atributos da plataforma Instagram e conhecimento teórico sobre marketing. Isto porque, os dados analisados entre publicação e engajamento não configuraram no impacto ou alcance possível desta ferramenta.

Quanto a descrição acima, é válido ressaltar que existe uma preferência, destes profissionais em atribuir valor as postagens, onde o corpo vincula-se ao treino, emitindo, que na prática do exercício físico regular existe uma progressão de resultados positivos, o que automaticamente conduz ao espectador um comportamento motivacional. Outro aspecto a ser levado em consideração é que a figura do personal estabelece o vínculo do resultado alcançado.

Quadro 1 Frequência de postagem, percentual médio de engajamento entre categoria e conteúdo.

\begin{tabular}{|c|c|c|c|}
\hline Sujeito & Postagem & $\%$ Engajamento & Categoria/Conteúdo \\
\hline 1 & 2 & 4,3282 & Corpo/Treino \\
\hline 2 & 1 & 0,7818 & Corpo/Treino \\
\hline \multirow{2}{*}{3} & \multirow{2}{*}{3} & 0,7500 & Corpo/Treino; \\
\hline & & 1,2083 & Pessoal/Pessoal \\
\hline 4 & 2 & 0,9051 & Exercício/motivacional \\
\hline \multirow{2}{*}{5} & \multirow{2}{*}{3} & 0,5411 & Exercício/treino \\
\hline & & 0,4529 & Exercício/motivacional \\
\hline 6 & 1 & 1,0551 & Conhecimento/inform. \\
\hline \multirow{3}{*}{7} & \multirow{3}{*}{4} & 0,0200 & Corpo/motivacional \\
\hline & & 0,0327 & Corpo/corpo \\
\hline & & 0,0122 & Conhecimento/inform. \\
\hline \multirow{4}{*}{8} & \multirow{4}{*}{5} & 0,3473 & Pessoal/pessoal \\
\hline & & 0,4105 & Exercício/marketing \\
\hline & & 1,3842 & Exercício/motivacional \\
\hline & & 1,1684 & Exercício/treino \\
\hline \multirow{2}{*}{9} & \multirow{2}{*}{3} & 0,2187 & Corpo/marketing \\
\hline & & 0,2880 & Corpo/motivacional \\
\hline \multirow{3}{*}{10} & \multirow{3}{*}{12} & 0,2441 & Corpo/treino \\
\hline & & 0,2511 & Corpo/equivoco \\
\hline & & 0,2219 & Corpo/motivacional \\
\hline
\end{tabular}


Analisar separadamente a emissão da imagem e a transmissão do conteúdo, poderia causar inversão de sentidos sobre os posts publicados. Assim para melhor compreensão da imagem publicada e do conteúdo foram criadas categorias simbólicas, onde dentre elas a de maior engajamento encontrada foi as publicações onde vincularam a figuração do corpo (imagem) em relação ao treino (texto), tendo como percentual $1,12 \%$. A segunda categoria de maior engajamento foi de exercício associado ao aspecto motivacional, com 1,00\% (Quadro 2).

Quadro 2 - Média da porcentagem de engajamento por categoria e conteúdo

\begin{tabular}{|c|c|}
\hline Categoria (imagem) / Conteúdo (texto) & Média \\
\hline Corpo / Treino & 1,1230 \\
\hline Corpo / motivacional & 0,2025 \\
\hline Corpo / equivoco & 0,2511 \\
\hline Corpo / marketing & 0,2187 \\
\hline Pessoal / Pessoal & 0,9213 \\
\hline Conhecimento / Informativo & 0,5336 \\
\hline Exercício / motivacional & 1,0063 \\
\hline Exercício / treino & 0,7502 \\
\hline Exercício / marketing & 0,4105 \\
\hline
\end{tabular}

\section{CONCLUSÃO}

De acordo com o objetivo conclui-se que os personal trainers analisados necessitam maior conhecimento da utilização da ferramenta Instagram, bem como o conhecimento da melhor forma de alcançar o público que compraria o seu produto. No entanto cabe dizer que a ferramenta é nova na utilização de marketing, estando em constante atualização.

Diante das análises feitas a dinâmica entre o transmissor e o espectador se deu mais efetivamente quando o transmissor publicou a imagem do corpo sendo ela em transformação ou evidenciando, o padrão desejado de corpo nos tempos atual. Outro aspecto com maior influência foi a publicação de exercício unindo com frases motivacionais.

\section{REFERÊNCIAS}


BOSSLE, C. B.. 'Personal Trainer \& Cia': Noções de marketing na literatura sobre treinamento personalizado. Universidade Federal do Rio Grande do Sul. Escola de Educação Física. Programa de Pós-Graduação em Ciências do Movimento Humano. Porto Alegre. 2009.

BRUGGER, A. S. M. F.; PRATES, O. P; Silva. W. T. A Importância do Marketing Pessoal para o sucesso de uma Carreira Profissional Segundo Profissionais da área de Recursos Humanos da Cidade de Montes Claros - MG, Brasil. E3 Revista de Economia, Empresas e Empreendedores na CPLP. Volume 2 número 2. Balneário Camboriú - SC. 2016

CARDOSO, D. P.; PINTO, M. M. M.. As redes sociais como ferramentas de divulgação de eventos. Fasci-Tech - Periódico Eletrônico da FATEC-São Caetano do Sul. São Caetano do Sul, v. 1, n. 5, Out/Dez 2011, p. 30 a 40.

DOMINGUES, L. A. F.. Manual do Personal Trainer Brasileiro. Edição 5. Editora Cone. São Paulo. 2015.

GOMES, C. F.; REIS, H. M.. Marketing digital: sites $x$ redes sociais no Brasil. Revista Interface Tecnológica da FATEC Taquaritinga .p. 53 - 62. SP. 2016.

O'REILLY, T.. What Is Web 2.0: Design Patterns and Business Models for the Next Generation of Software. Communications \& Strategies. 1, 17-38. 2007.

PELLANDA, E. C.; STRECK, M.. Instagram como interface da comunicação móvel e Ubíqua. Sessões do imaginário. Porto Alegre. 2017.

RAMOS, L. D. S.. Marketing digital em redes sociais: um estudo exploratório sobre a influência da promoção online. Instituto federal de educação, ciência e tecnologia. Caraguatatuba/SP, 2015.

SANTOS, T. C. D.. Redes sociais como ferramenta de marketing: facebook. Fundação Educacional do Município de Assis - FEMA. Assis, 2012.

SPACOV, Y. F.. O personal trainer: uso de estratégias de marketing na atividade profissional. Universidade nove de julho - UNINOVE. São Paulo. 2016.

VIEIRA, M. D. P.. As influenciadoras digitais no Instagram e o empreendedorismo de si: o caso do fitness. Universidade Federal de Juiz de Fora, Faculdade de Educação Física. Juiz de Fora. 2017. 